\title{
Índice de Bem-Estar Econômico: uma Proposta para os Estados Brasileiros
}

\section{Index of Economic Well-Being: a Proposal for the Brazilian States}

\author{
Cláudia Bueno Rocha Vidigal* \\ Ana Lucia Kassouf** \\ Vinícius Gonçalves Vidigal***
}

\begin{abstract}
Resumo: O presente artigo tem por objetivo a construção de um Índice de Bem-Estar Econômico (IBEE) para as unidades da federação brasileira, considerando os anos de 2002 e 2008. Especificamente, busca-se verificar os níveis de bem-estar econômico e de seus subcomponentes, além de compará-los entre os estados brasileiros. $\mathrm{O}$ índice proposto é composto por quatro dimensões distintas: "Fluxos de consumo", "Riqueza real - Legado intergeracional", "Equidade" e "Seguridade econômica". Os principais resultados demonstraram que, independentemente da ponderação utilizada, Santa Catarina foi o estado brasileiro que apresentou o maior bem-estar econômico em relação aos demais. Por outro lado, Alagoas foi o estado com pior desempenho, ocupando a última posição do ranking em todas as análises. Considerando a necessidade de construção de uma medida sintética de bem-estar econômico e tendo em vista a relevância de indicadores para subsidiar a implementação e monitoramento de políticas públicas, o IBEE apresenta-se como um índice capaz de mensurar de maneira mais adequada os distintos aspectos associados a um padrão de vida decente.
\end{abstract}

Palavras-chave: Bem-estar econômico. Estados brasileiros. Indicador sintético.

Abstract: This study aims to build an Index of Economic Well-Being (IEWB) for the Brazilian states in the years 2002 and 2008. Specifically, we determine the levels of economic wellbeing and its sub-components. The proposed index is composed of four distinct dimensions: "Consumption Flows", "Real Wealth - Intergenerational Legacy", "Equity" and "Economic Security". The main results showed that, regardless of the weighting scheme, Santa Catarina had the highest economic well-being compared to the other states. In contrast, Alagoas was the state with the poorest result across all analyses. Considering the need of a synthetic measure of economic well-being and the importance of indices for the implementation and evaluation of public policies, the IEWB consists of an index capable of measuring more properly the various aspects associated with a decent standard of living.

Keywords: Economic Well-Being. Brazilian states. Synthetic indicator.

* Doutora em Economia Aplicada pela University of Minnesota. E-mail: claudiabrvidigal@gmail. com

* $\quad$ Doutora em Economia Aplicada pela University of Minnesota. Professora da Escola Superior de Agricultura Luiz de Queiroz (ESALQ) da Universidade de São Paulo (USP). E-mail: anakassouf@ usp.br

*** Doutor em Economia Aplicada pela University of Minnesota. Professor da Universidade Estadual do Paraná (Unespar). E-mail: viniciusgv@gmail.com 


\section{1 lntrodução}

Uma das grandes preocupações dos formuladores de políticas públicas em anos recentes tem sido o nível de bem-estar da sociedade, em suas distintas esferas, assim como a forma com que o mesmo se define e pode ser mensurado.

Amplamente relacionado à forma com que os indivíduos valorizam as temáticas humanas, sociais e econômicas, o bem-estar pode ser vislumbrado sob diferentes aspectos; no entanto, todos intimamente atrelados entre si. Uma das formas de se observar o bem-estar é através da dimensão econômica, cujo enfoque é direcionado aos elementos que proporcionam maior nível de comodidade econômica e satisfação individual ou coletiva. De acordo com a Commission for Rural Communities (2010), o bem-estar econômico de um indivíduo ou de uma comunidade é determinado pela capacidade de acesso a bens, serviços e oportunidades econômicas geradas por atividades sustentáveis nos âmbitos ambiental e social. Destarte, tudo aquilo que contribui positivamente para ampliar o nível de contentamento econômico mostra-se relevante ao cômputo dessa forma de bem-estar.

O bem-estar econômico, segundo Osberg e Sharpe (2002), depende de uma ampla gama de variáveis, as quais podem ser agrupadas em quatro dimensões: fluxos de consumo pessoal; estoques de riqueza; distribuição de renda e seguridade econômica. De acordo com os autores, o nível de bem-estar econômico não está sujeito apenas à satisfação individual e no momento presente, mas também à satisfação de toda a sociedade e sua segurança econômica futura. A preocupação com o bem-estar coletivo faz com que os indivíduos valorizem políticas que tenham por objetivo a distribuição de renda e a sustentabilidade, sobretudo devido ao grande efeito sobre toda a sociedade. ${ }^{1}$

A necessidade de se conhecer o nível de bem-estar de uma sociedade, assim como mensurar os resultados de uma política focalizada, fez com que surgissem e fossem disseminados diversos instrumentos estatísticos de medição, os chamados "indicadores econômicos e sociais". Conforme destacam Guimarães e Jannuzzi (2004), a escassez de recursos e a necessidade de correto direcionamento de políticas propiciaram o crescimento do interesse em estatísticas, indicadores e índices periódicos. Tais instrumentos são de suma relevância ao planejamento de políticas públicas, sobretudo para subsidiar o processo de implantação, monitoramento e avaliação das mesmas.

$1 \quad$ Para a análise de bem-estar econômico e distribuição de renda, ver os trabalhos de Figueirêdo (2007) e Figueirêdo e Ziegelmann (2009). 
A avaliação do padrão de bem-estar de uma sociedade deve considerar distintos aspectos. Todavia, devido à dificuldade de operacionalização, bem como à complexidade desses fatores, o foco analítico tem-se restringido apenas à variável renda. Uma das principais e mais antigas medidas de bem-estar econômico conhecidas é o Produto Interno Bruto (PIB), e sua extensão, o PIB per capita. Amplamente utilizado, o PIB per capita ganhou o status de indicador de bem-estar econômico a partir da década de 1950, sobretudo devido às seguintes vantagens: ser facilmente calculado através de base de dados disponíveis na maior parte dos países; permitir a comparabilidade entre estes, e também por ser de fácil compreensão. No entanto, exclui de sua extensão variáveis que captam a distribuição de renda, a expectativa de vida, o nível de gastos desagregados, o estoque de recursos naturais, o nível de desemprego, o estoque de capital humano, entre outras características que são de extrema importância à mensuração do nível de bem-estar econômico de uma sociedade. Ademais, não considera o nível de sustentabilidade nem mesmo o legado intergeracional, ou seja, não permite verificar em que condições as gerações futuras viverão. Possui ainda a desvantagem de ser uma medida agregada que pode sofrer alterações resultantes de flutuações cambiais, principalmente em economias instáveis.

Em virtude das diversas críticas pelas quais passava o PIB per capita, inúmeros pesquisadores se empenharam no intuito de formular novos indicadores de bem-estar. Não apenas refletindo os aspectos econômicos, surge em 1990 o Índice de Desenvolvimento Humano (IDH), elaborado por Amartya Sen e Mahbub ul Haq (ANAND; SEN, 1994). Com base em um reduzido número de dimensões, o IDH destaca-se pela fácil interpretação, o que constitui um fator relevante à transparência e simplicidade na transmissão dos resultados a um público amplo e diversificado. Entretanto, de forma análoga ao PIB per capita, o IDH apresenta diversas limitações, muitas delas semelhantes às supracitadas. O IDH é ainda criticado pelo fato de não considerar as particularidades regionais, além de não estabelecer critérios para a ponderação atribuída a cada um de seus componentes.

Embora seja crescente o esforço em mensurar o bem-estar econômico dos indivíduos por parte das universidades, agências estatísticas e centros de pesquisa, especialmente devido à necessidade de acompanhamento dos resultados de políticas públicas voltadas à melhoria da qualidade de vida, os índices até então construídos não permitem conhecer exatamente o nível de bem-estar econômico de uma sociedade. Tal limitação deve-se à forma como são construídos, não incluindo variáveis que captem a satisfação econômica a partir do consumo, da riqueza e da seguridade econômica.

Há na literatura econômica uma escassez de trabalhos que busquem mensurar o nível de bem-estar econômico, sobretudo no que se refere aos estados brasileiros, onde a problemática recai especialmente na indisponibilidade de in- 
formações. Afora isso, vários são os métodos de cálculo utilizados, assim como ponderações conferidas às variáveis consideradas. A inexistência de um consenso acerca da definição de bem-estar econômico, e mesmo a utilização de metodologia inadequada, permite que interpretações errôneas sejam realizadas a partir dos indicadores existentes.

Tendo em vista a importância de indicadores para subsidiar a implementação e monitoramento de políticas públicas, assim como para disponibilizar informações transparentes à população, a construção de um índice de bem-estar econômico que busque captar a realidade econômica e regional dos estados brasileiros se justifica. A possibilidade de cálculo conjunto, sob a forma de indicador sintético de bem-estar econômico, confere ao índice a qualidade necessária para a confiabilidade dos resultados obtidos. Sua principal contribuição está no fato de agregar variáveis econômicas e sociais em um único indicador, permitindo a comparação entre estados e ao longo do tempo.

Diante do exposto, o presente estudo tem por objetivo a construção de um Índice de Bem-Estar Econômico (IBEE) para as unidades da federação brasileira, considerando os anos de 2002 e 2008. Especificamente, busca-se verificar os níveis de bem-estar econômico e de seus subcomponentes, além de compará-los entre os estados brasileiros. O IBEE é sugerido como um indicador sintético alternativo de bem-estar econômico, no qual os diferentes aspectos relacionados ao acesso aos recursos econômicos, tais como consumo, riqueza, equidade e seguridade econômica, são sintetizados em um único índice. Trata-se de uma proposta alternativa aos indicadores existentes, sobretudo ao PIB per capita, o qual desconsidera fatores essenciais no âmbito da satisfação econômica.

\section{Procedimentos Metodológicos}

A construção do Índice de Bem-Estar Econômico (IBEE) proposto é realizada com base em Osberg (1985) e Osberg e Sharpe (1998, 2002, 2009), trabalhos nos quais a principal hipótese é de que o bem-estar econômico de uma sociedade depende dos níveis de consumo e de acumulação, bem como da desigualdade de renda e inseguridade inerente à distribuição dos agregados macroeconômicos. Cabe salientar que o modelo proposto de indicador assume um conjunto de condições necessárias, mas não suficientes, para que o bem-estar econômico seja válido para uma sociedade. Admite-se um agente representativo da sociedade avesso ao risco, o qual, a partir de suas expectativas, considera um fluxo de renda de acordo com a distribuição atual do mesmo. Considera-se ainda que esse agente representativo possui uma função utilidade em que tanto o consumo pessoal quanto o legado às gerações futuras são avaliados. Ademais, pressupõe-se que os fluxos de renda dos indivíduos podem ser acometidos por choques econômicos imprevisí- 
veis e, além disso, que os mercados financeiros e as políticas públicas nem sempre produzem automaticamente um ótimo social da taxa de poupança agregada. ${ }^{2}$

O IBEE é elaborado a partir de indicadores individuais que compreendem as quatro principais dimensões ou componentes do bem-estar econômico: Fluxos de consumo; Riqueza real - Legado intergeracional; Equidade e Seguridade econômica, conforme Quadro 1. Deve-se destacar que, devido à indisponibilidade de informações para as localidades consideradas e adaptação à realidade brasileira, algumas variáveis e indicadores foram omitidos, não representando prejuízos para o resultado do índice. Um grande diferencial do IBEE construído neste estudo está no fato de ter-se criado um novo indicador, o de risco de violência. Tal indicador surgiu no intuito de incluir o impacto da violência sobre o bem-estar econômico dos indivíduos, sobretudo devido ao fato de serem observados elevados níveis de criminalidade no Brasil. Em 2005, as taxas de homicídios intencionais no país foram uma das maiores do mundo, chegando a mais de 29 pessoas a cada 100.000 habitantes (WORLD BANK, 2011). São conhecidos e bastante discutidos na literatura os impactos econômicos da violência sobre uma sociedade, especialmente no que se refere a privações de bem-estar. Desta forma, mostra-se relevante a inclusão de uma variável que busque refletir o risco de violência sobre o bem-estar econômico.

2 A discussão completa acerca dessas condições pode ser encontrada em Osberg (1985). 
Quadro 1 - Estrutura do Índice de Bem-Estar Econômico

\begin{tabular}{|c|c|c|}
\hline Dimensões & Indicador & Variável \\
\hline \multirow{2}{*}{ Fluxos de consumo } & Consumo privado & $\begin{array}{l}\text { Gasto privado de consumo final } \\
\text { per capita }\end{array}$ \\
\hline & Consumo público & $\begin{array}{l}\text { Gasto de consumo final do gover- } \\
\text { no per capita }\end{array}$ \\
\hline \multirow{4}{*}{$\begin{array}{l}\text { Riqueza real - Legado } \\
\text { intergeracional }\end{array}$} & Capital físico & $\begin{array}{l}\text { Formação bruta de capital fixo } \\
\text { (FBKF) per capita }\end{array}$ \\
\hline & Capital humano & $\begin{array}{l}\text { Despesa pública per capita com } \\
\text { educação } \\
\text { Despesa privada per capita com } \\
\text { educação }\end{array}$ \\
\hline & $\begin{array}{l}\text { Gastos com Pesquisa } \\
\text { e desenvolvimento }\end{array}$ & $\begin{array}{l}\text { Gasto público per capita com pes- } \\
\text { quisa e desenvolvimento (PED) }\end{array}$ \\
\hline & Débito público & Dívida líquida real per capita \\
\hline \multirow{2}{*}{ Equidade } & $\begin{array}{l}\text { Desigualdade de } \\
\text { renda }\end{array}$ & Índice de Gini \\
\hline & $\begin{array}{l}\text { Intensidade } \mathrm{da} \\
\text { pobreza }\end{array}$ & Índice FGT \\
\hline \multirow{4}{*}{$\begin{array}{l}\text { Seguridade } \\
\text { econômica }\end{array}$} & Risco de desemprego & Taxa de desemprego \\
\hline & $\begin{array}{l}\text { Risco financeiro as- } \\
\text { sociado à doença }\end{array}$ & $\begin{array}{l}\text { Despesa pública per capita com } \\
\text { saúde } \\
\text { Despesa privada per capita com } \\
\text { saúde }\end{array}$ \\
\hline & $\begin{array}{l}\text { Risco de pobreza em } \\
\text { idade avançada }\end{array}$ & $\begin{array}{l}\text { Taxa de pobreza entre pessoas } \\
\text { com idade acima de } 65 \text { anos }\end{array}$ \\
\hline & Risco de Violência & Taxa de homicídios \\
\hline
\end{tabular}

Fonte: Elaboração própria.

A dimensão "Fluxos de Consumo" mostra-se, provavelmente, como o fator de mais clara influência sobre o bem-estar econômico dos indivíduos e suas famílias (JURADO; PEREZ-MAIO, 2011). Deve-se considerar a importância em serem obtidas variáveis que sejam capazes de refletir o consumo de bens e serviços, tanto por parte das famílias (gasto privado de consumo final) quanto pelo governo (gasto de consumo final do governo). Ainda referente à supracitada dimensão, há diversos fatores importantes, no entanto, devido à dificuldade de mensuração, es- 
ses não foram incorporados ao índice. Dentre os fatores estão o tempo de lazer, a economia informal, os custos com a jornada de trabalho e o consumo de produtos prejudiciais à saúde ou de produtos ilegais que levam ao crime.

A dimensão "Riqueza Real - Legado Intergeracional", a qual inclui capital físico e humano, gastos com pesquisa e desenvolvimento e dívida pública, procura medir o legado que a sociedade atual irá transferir para as futuras gerações. O montante de capital acumulado poderá servir como estrutura produtiva de uma sociedade futura. Além disso, conforme destacam Jurado e Perez-Maio (2011), essa transferência deve incluir ainda um patrimônio ambiental, uma base sólida de pesquisa e desenvolvimento, bem como uma dívida pública controlada. As variáveis utilizadas para mensurar a riqueza real e o legado intergeracional são: a formação bruta de capital fixo per capita; as despesas públicas e privadas per capita com educação, considerando os três níveis de ensino; os gastos públicos per capita com pesquisa e desenvolvimento e ainda a dívida pública real per capita. Cabe destacar que esta última variável entra no cômputo do IBEE como algo maléfico ao bem-estar econômico, ou seja, aqueles estados que têm uma elevada dívida pública devem estar em colocações mais baixas no ranking.

Indicadores de desigualdade de renda e intensidade de pobreza são utilizados para mensurar a dimensão "Equidade". Elevados níveis de pobreza, assim como uma distribuição de renda desigual, são considerados elementos prejudiciais ao bem-estar econômico de uma sociedade, uma vez que causam privações no consumo e na acumulação das famílias. Para medir a desigualdade de distribuição de renda utiliza-se o Índice de Gini, um dos principais indicadores com tal finalidade (LANGONI, 2005; STIGLITZ; SEM; FITOUSSI, 2009). A intensidade da pobreza é obtida a partir do Índice de Foster, Greer e Thorbecke (FGT), o qual pode ser representado da seguinte forma:

$$
\varphi_{j}=\frac{1}{n_{j} z^{2}} \sum_{i=1}^{k_{i}}\left(z-X_{j}\right)^{2}
$$

em que:

$\varphi_{\mathrm{j}}$ é o índice de pobreza da localidade $\mathrm{j}, 0<\varphi_{\mathrm{j}}<1, \mathrm{j}=1, \ldots, \mathrm{J}$;

$\mathrm{n}_{\mathrm{j}}$ é a população total da localidade $\mathrm{j}$;

z é a linha de pobreza; ${ }^{3}$

$\mathrm{k}_{\mathrm{j}}$ é o número de indivíduos pobres da localidade j;

$\mathrm{X}_{\mathrm{ij}}$ é a renda do i-ésimo indivíduo da localidade $\mathrm{j}$.

3 Utiliza-se neste estudo a linha de pobreza de meio salário mínimo. A justificativa para tal decisão está relacionada ao fato de não existirem linhas de pobreza estimadas para os estados brasileiros. Encontram-se na literatura apenas algumas estimativas para as diferentes regiões metropolitanas. Afora isto, conforme destacado por Soares (2009), não há um consenso sobre a linha de pobreza ideal, tampouco existe uma linha de pobreza oficial. 
De acordo com Rocha (2006), o índice FGT possui a vantagem de atender às propriedades desejáveis de um indicador de pobreza, além de ser de fácil operacionalização. Ademais, destaca-se o fato de o índice ter sido potencializado de forma que maior importância fosse dada à intensidade da pobreza, ou seja, o hiato de renda de cada um dos indivíduos pobres foi elevado à potência quadrática.

A dimensão "Seguridade Econômica" é medida pelo risco de desemprego, risco financeiro associado à doença, risco de pobreza em idade avançada e pelo risco de violência. A referida dimensão é considerada, segundo Jurado e Perez-Maio (2011), uma das principais causas de ausência de bem-estar econômico. Os problemas econômicos decorrentes do desemprego, de doenças, da pobreza e da violência reduzem o bem-estar dos indivíduos não apenas no momento presente, mas também trazem incertezas quanto ao padrão de vida futuro. A variável utilizada para mensuração do risco de pobreza é a taxa de desemprego. O risco financeiro associado à doença é medido pelas despesas públicas e privadas per capita com saúde e parte do pressuposto de que, quanto maiores forem esses gastos, mais elevadas serão as perdas de rendimentos, ou seja, serão maléficos ao bem-estar econômico. Isto se justifica pelo fato de que, no Brasil, os dispêndios com saúde destinam-se especialmente à tratamentos após a incidência de doenças e não à sua prevenção. Afora isto, o risco de pobreza em idade avançada é obtido pela taxa de pobreza entre pessoas com idade superior a 65 anos e o risco de violência é mensurado a partir da taxa de homicídios. Admite-se que quanto maiores forem as taxas de homicídios, piores serão os níveis de bem-estar econômico da sociedade. Isso se deve ao fato de que privações no consumo e na acumulação de renda ocorrerão para a população que for acometida por elevados níveis de violência sob a forma de homicídios. De acordo com Andrade e Peixoto (2007), a violência gera uma redução de bem-estar para a sociedade, a qual se reflete na perda direta de qualidade de vida e no aumento de recursos financeiros alocados para sua prevenção e combate.

\subsection{Técnica de Linearização}

Utiliza-se para o cálculo do IBEE a Técnica de Linearização Min-Máx, ${ }^{4}$ que consiste em padronizar as variáveis que compõem os indicadores. Para tanto, uma

4 Há na literatura outras formas de linearização como, por exemplo, a variante do Método Min-Máx dada pela expressão:

$I_{i j}^{t}=\frac{X_{i j}^{t}-\min _{t \in T} \min _{k}\left(X_{i k}^{t}\right)}{\max _{t \in T} \max _{t}\left(X_{t k}^{t}\right)-\min _{t \in T} \min \left(X_{i k}^{t}\right)}$, em que os valores mínimos e máximos são calculados entre todas as localidadês e todos os períodos de tempo. No entanto, essa transformação não é estável quando são inseridas variáveis de novos anos na análise. Dessa forma, para manter a comparabilidade entre as variáveis novas e as já existentes, os indicadores devem ser recalculados, tornando a prática quase inviável (ORGANIZAÇÃO PARA A COOPERAÇÃO E DESENVOLVIMENTO ECONÔMICO, 2008). 
estimação é realizada para o mais elevado e mais reduzido valor que representa uma determinada variável dentre os valores observados para todos os estados em um ano específico, de tal forma que seja possível calcular cada indicador.

Para a situação em que uma elevação de determinada variável implique um aumento de bem-estar econômico, a linearização segue a seguinte formulação:

$$
I_{i j}^{t}=\frac{X_{i j}^{t}-\min _{k}\left(X_{i k}^{t}\right)}{\max _{k}\left(X_{i k}^{t}\right)-\min _{k}\left(X_{i k}^{t}\right)}
$$

em que $\mathrm{I}_{\mathrm{ij}}$ é o indicador i para a localidade j; j $=1, \ldots, \mathrm{k}$; e $0<\mathrm{I}_{\mathrm{ij}}<1$.

De modo inverso, se o aumento de uma variável provoca redução no nível de bem-estar, a linearização realiza-se da seguinte forma:

$$
I_{i j}^{t}=\frac{\max _{k}\left(X_{i k}\right)-X_{i j}}{\max _{k}\left(X_{i k}\right)-\min _{k}\left(X_{i k}\right)}
$$

em que $I_{i j}$ é o indicador $i$ para a localidade $j ; j=1, \ldots, k$; e $0<I_{i j}<1$.

O cálculo do IBEE é realizado conforme a seguinte especificação:

$$
\begin{aligned}
& I B E E=P_{1}\left(p_{1} C+p_{2} G\right)+P_{2}\left(p_{3} K+p_{4} H+p_{5} P e D-p_{6} D P\right)+P_{3}\left(-p_{7} D R-p_{8} I P\right)+ \\
& P_{4}\left(-p_{9} R D E S-p_{10} R D O-p_{11} R P I A-p_{12} R V\right)
\end{aligned}
$$

em que: $C=$ consumo privado; $G=$ consumo público; $K=$ capital físico; $H=$ capital humano; $P e D=$ gastos com pesquisa e desenvolvimento; $D P=$ dívida pública; $D R=$ desigualdade de renda; $I P=$ intensidade da pobreza; $R D E S=$ risco de desemprego; $R D O=$ risco financeiro associado à doença; $R P I A=$ risco de pobreza em idade avançada; $R V=$ risco de violência.

A obtenção dos valores das dimensões a partir dos indicadores se dá com base em ponderações uniformes. Ademais, emprega-se a devida técnica de linearização correspondente a cada indicador. ${ }^{5}$

5 Uma técnica alternativa para a obtenção das ponderações dos indicadores e, posteriormente, das dimensões é a Análise Fatorial, tal como utilizada por Jurado e Perez-Maio (2011). No entanto, a utilização desse método, que busca descrever o comportamento de um conjunto de variáveis por meio de um número menor de indicadores, denominados fatores, mostra-se inadequada para a presente análise. Uma vez que se busca a obtenção de apenas uma variável latente final, ou seja, um fator que representasse as quatro dimensões do bem-estar econômico, incorre-se no problema do baixo poder explicativo do mesmo. A parcela da variabilidade das dimensões explicada por um único fator resultante, como poderia se esperar pelo número reduzido de variáveis originais (dimensões), mostra-se muito reduzida. 
A posterior construção do IBEE é constituída pelo agrupamento das quatro dimensões, atribuindo-se, inicialmente, iguais ponderações para as mesmas $\left(P_{1}=\right.$ $\left.P_{2}=P_{3}=P_{4}=0,25\right)$. Subsequentemente, são utilizadas ponderações distintas ${ }^{6} \mathrm{de}$ tal forma que seja possível optar pela combinação mais apropriada às características dos estados brasileiros e evitar possíveis arbitrariedades na escolha do melhor peso a ser atribuído a cada dimensão.

\subsection{Fonte de Dados}

O presente trabalho tem como base dados referentes às unidades da federação brasileira, que incluem vinte e seis estados e o Distrito Federal, para os anos de 2002 e 2008. A restrição quanto ao número de anos observados deve-se à indisponibilidade de algumas variáveis utilizadas no cômputo do IBEE, sobretudo àquelas referentes aos gastos familiares, provenientes das Pesquisas de Orçamentos Familiares (POFs).

O consumo privado foi obtido a partir das despesas totais per capita junto à base de dados das POFs de 2002-2003 e 2008-2009 (IBGE, 2011a). O consumo público, dado pelos gastos de consumo final per capita dos governos estaduais, é disponibilizado pela Secretaria do Tesouro Nacional (BRASIL, 2011a). Utilizou-se como proxy para a formação bruta de capital fixo (FBKF) a variável consumo de energia elétrica industrial, ${ }^{7}$ oriunda da Empresa de Pesquisa Energética (BRASIL, 2011c). As despesas públicas per capita com educação foram obtidas através da Secretaria do Tesouro Nacional (BRASIL, 2011a) e as despesas privadas per capita com educação a partir das POFs de 2002-2003 e 2008-2009 (IBGE, 2011a). As despesas públicas per capita com ciência e tecnologia foram empregadas como proxy para a variável gastos com pesquisa e desenvolvimento, ${ }^{8}$ tendo como fonte a Secretaria do Tesouro Nacional (BRASIL, 2011a). A partir dessa mesma fonte, foram coletadas as informações sobre a dívida pública dos estados, a qual foi posteriormente dividida pela população total de cada localidade. O Índice de Gini, que mede a desigualdade de distribuição de renda de uma população, foi obtido através do Instituto de Pesquisa Econômica Aplicada (2011). As variáveis utilizadas para o cálculo do Índice FGT - população total do estado, número de pessoas pobres e renda total das mesmas - assim como a taxa de pobreza entre pessoas

$6 \quad$ Nesta etapa, o IBEE é calculado de quatro maneiras distintas, cada qual atribuindo peso mais elevado para uma dimensão específica.

7 A utilização do consumo de energia elétrica industrial como proxy para investimento ou FBKF deve-se ao fato de não existirem estimativas específicas para os estados brasileiros. Tal procedimento está em conformidade com outros trabalhos, como o de Amorim, Scalco e Braga. (2008) e de Cangussu, Salvato e Nakabashi (2010).

8 De acordo com o Ministério de Ciência e Tecnologia, o agregado Ciência e Tecnologia (CET) é dado pelo somatório entre Pesquisa e Desenvolvimento (PED) e atividades científicas e técnicas correlatas (BRASIL, 2011b). 
com 65 anos ou mais, foram extraídas dos microdados das Pesquisas Nacionais por Amostra de Domicílios (PNADs) dos anos de 2002 e 2008, divulgadas pelo IBGE (2011b). A taxa de desemprego, assim como a população total, teve como fonte o Instituto de Pesquisa Econômica Aplicada (2011). As despesas públicas per capita com saúde foram retiradas dos relatórios de Execução Orçamentária dos Estados, divulgados pela Secretaria do Tesouro Nacional (BRASIL, 2011a). As despesas privadas per capita com saúde e a taxa de homicídios tiveram como fonte as POFs de 2002-2003 e 2008-2009 - IBGE (2011a) e a base de dados do Departamento de Informática do SUS (DATASUS, 2011), respectivamente. É importante salientar que todos os valores financeiros foram atualizados para o ano mais recente da análise, 2008, através do Índice Geral de Preços - disponibilidade interna (IGP-DI).

\section{Resultados e Discussões}

A presente seção apresenta os resultados e discussões para cada uma das dimensões do Índice de Bem-Estar Econômico, bem como os resultados do índice construído a partir de suas quatro dimensões.

\subsection{As Dimensões do IBEE}

A construção do IBEE tem início com a linearização de todas as variáveis que o compõem, tornando-as padronizadas antes do cálculo dos indicadores. Para essa etapa é necessário estimar o mais elevado e o mais reduzido valor de cada variável a partir dos valores observados para todos os estados, de forma a padronizá-los numa escala entre zero e um.

Em seguida, cada um dos indicadores é obtido através das variáveis linearizadas, sendo utilizadas ponderações uniformes para o caso em que sejam compostos, ou seja, exista mais de uma variável em sua definição. Embora alguns estudiosos chamem a atenção para a possibilidade de ponderações distintas, a escolha se dá, de certa forma, de maneira arbitrária, uma vez que cabe ao pesquisador a definição dos pesos a serem atribuídos a cada variável.

$\mathrm{Na}$ etapa sequencial, são construídas as dimensões compreendendo os respectivos indicadores. É importante salientar que cada dimensão é composta por pelo menos dois indicadores, sendo novamente utilizadas ponderações uniformes. Dessa forma, no intuito de se observar a situação dos estados brasileiros, tanto em cada ano analisado quanto em tendência, faz-se o ranqueamento dos mesmos de acordo com cada dimensão do IBEE.

A Tabela 1 apresenta os resultados para a dimensão "Fluxos de Consumo", composta pelos indicadores consumo privado e consumo público. 
Tabela 1 - Valores da dimensão "Fluxos de consumo" e ranqueamento segundo as unidades da federação (2002 e 2008)

\begin{tabular}{|c|c|c|c|c|c|}
\hline Estado & 2002 & Posição & Estado & 2008 & Posição \\
\hline Distrito Federal & 1,000 & 1 & Distrito Federal & 0,941 & 1 \\
\hline Rio de Janeiro & 0,542 & 2 & São Paulo & 0,701 & 2 \\
\hline São Paulo & 0,503 & 3 & Rio de Janeiro & 0,677 & 3 \\
\hline Rio Grande do Sul & 0,431 & 4 & Amapá & 0,571 & 4 \\
\hline Santa Catarina & 0,380 & 5 & Acre & 0,558 & 5 \\
\hline Acre & 0,334 & 6 & Espírito Santo & 0,558 & 6 \\
\hline Paraná & 0,333 & 7 & Santa Catarina & 0,556 & 7 \\
\hline Amapá & 0,330 & 8 & Roraima & 0,542 & 8 \\
\hline Espírito Santo & 0,328 & 9 & Rio Grande do Sul & 0,542 & 9 \\
\hline Roraima & 0,327 & 10 & Mato Grosso do Sul & 0,521 & 10 \\
\hline Mato Grosso do Sul & 0,277 & 11 & Tocantins & 0,436 & 11 \\
\hline Minas Gerais & 0,273 & 12 & Rondônia & 0,432 & 12 \\
\hline Mato Grosso & 0,270 & 13 & Paraná & 0,406 & 13 \\
\hline Tocantins & 0,254 & 14 & Mato Grosso & 0,403 & 14 \\
\hline Rondônia & 0,242 & 15 & Minas Gerais & 0,401 & 15 \\
\hline Goiás & 0,239 & 16 & Goiás & 0,373 & 16 \\
\hline Amazonas & 0,188 & 17 & Sergipe & 0,256 & 17 \\
\hline Sergipe & 0,165 & 18 & Amazonas & 0,254 & 18 \\
\hline Pernambuco & 0,139 & 19 & Rio Grande do Norte & 0,198 & 19 \\
\hline Bahia & 0,131 & 20 & Pernambuco & 0,192 & 20 \\
\hline Rio Grande do Norte & 0,117 & 21 & Bahia & 0,176 & 21 \\
\hline Ceará & 0,112 & 22 & Paraíba & 0,145 & 22 \\
\hline Pará & 0,070 & 23 & Pará & 0,121 & 23 \\
\hline Alagoas & 0,069 & 24 & Piauí & 0,110 & 24 \\
\hline Paraíba & 0,053 & 25 & Ceará & 0,061 & 25 \\
\hline Piauí & 0,048 & 26 & Alagoas & 0,045 & 26 \\
\hline Maranhão & 0,000 & 27 & Maranhão & 0,026 & 27 \\
\hline
\end{tabular}

Fonte: Elaboração própria.

É possível observar que, nos dois anos de análise, o Distrito Federal liderou o ranking da dimensão e o Maranhão teve o pior desempenho. Os bons resultados do Distrito Federal, sobretudo no ano de 2002, devem-se ao fato de o mesmo ter apresentado o maior consumo privado per capita (R\$14.268) e o maior consumo público per capita (R\$ 5.625). De modo inverso, o Maranhão apresentou em 2002 
os piores valores, tanto para o consumo privado per capita $(\mathrm{R} \$ 3.474)$ quanto para o consumo público per capita ( $\mathrm{R} \$ 1.010)$.

Outra análise relevante refere-se à inversão de posições ocorrida entre os estados do Rio de Janeiro e São Paulo nos anos 2002 e 2008, assim como a queda no ranqueamento verificada pelo Rio Grande do Sul, que passou do quarto lugar para o nono. Em relação a este último, o pior desempenho deve-se, principalmente, à menor elevação do consumo público per capita em 2008 em comparação aos demais estados. É possível observar ainda a presença do Amapá, em 2008, entre os quatro principais estados segundo a dimensão analisada. A principal justificativa para o bom desempenho do estado foi o elevado consumo público per capita, em torno de $\mathrm{R} \$$ 3.670. O gasto público do Amapá, embora bastante baixo quando comparado a outros estados ( $\mathrm{R} \$ 2,2$ bilhões), torna-se elevado ao ser ponderado pela população total (613 mil habitantes).

O ranqueamento dos estados segundo a dimensão "Riqueza Real - Legado Intergeracional" encontra-se na Tabela 2. Observa-se que, novamente, o Distrito Federal é aquele que apresenta o melhor valor para a dimensão nos dois anos analisados. O Paraná vem logo em seguida, em segundo lugar, também nos dois anos. A dimensão analisada foi uma das que mais exibiram variações com relação ao ranqueamento entre os estados, sobretudo o Acre, São Paulo, Pernambuco, Goiás e Rio Grande do Sul. 
Tabela 2 - Valores da dimensão "Riqueza real - Legado intergeracional" e ranqueamento segundo as unidades da federação (2002 e 2008)

\begin{tabular}{|c|c|c|c|c|c|}
\hline Estado & 2002 & Posição & Estado & 2008 & Posição \\
\hline Distrito Federal & 0,656 & 1 & Distrito Federal & 0,649 & 1 \\
\hline Paraná & 0,635 & 2 & Paraná & 0,565 & 2 \\
\hline São Paulo & 0,617 & 3 & Acre & 0,558 & 3 \\
\hline Pará & 0,512 & 4 & Pará & 0,540 & 4 \\
\hline Pernambuco & 0,499 & 5 & Minas Gerais & 0,532 & 5 \\
\hline Amapá & 0,496 & 6 & Espírito Santo & 0,517 & 6 \\
\hline Minas Gerais & 0,465 & 7 & Amapá & 0,516 & 7 \\
\hline Espírito Santo & 0,455 & 8 & Santa Catarina & 0,513 & 8 \\
\hline Santa Catarina & 0,455 & 9 & São Paulo & 0,485 & 9 \\
\hline Acre & 0,438 & 10 & Goiás & 0,485 & 10 \\
\hline Maranhão & 0,432 & 11 & Sergipe & 0,475 & 11 \\
\hline Sergipe & 0,388 & 12 & Amazonas & 0,467 & 12 \\
\hline Rio Grande do Sul & 0,338 & 13 & Roraima & 0,467 & 13 \\
\hline Roraima & 0,335 & 14 & Tocantins & 0,427 & 14 \\
\hline Rio Grande do Norte & 0,323 & 15 & Maranhão & 0,422 & 15 \\
\hline Ceará & 0,322 & 16 & Bahia & 0,370 & 16 \\
\hline Amazonas & 0,308 & 17 & Mato Grosso & 0,361 & 17 \\
\hline Tocantins & 0,295 & 18 & Rio Grande do Norte & 0,339 & 18 \\
\hline Rio de Janeiro & 0,292 & 19 & Rio de Janeiro & 0,338 & 19 \\
\hline Paraíba & 0,251 & 20 & Ceará & 0,327 & 20 \\
\hline Bahia & 0,245 & 21 & Pernambuco & 0,310 & 21 \\
\hline Mato Grosso & 0,216 & 22 & Rio Grande do Sul & 0,289 & 22 \\
\hline Alagoas & 0,212 & 23 & Paraíba & 0,274 & 23 \\
\hline Rondônia & 0,210 & 24 & Rondônia & 0,271 & 24 \\
\hline Piauí & 0,209 & 25 & Mato Grosso do Sul & 0,234 & 25 \\
\hline Goiás & 0,183 & 26 & Alagoas & 0,220 & 26 \\
\hline Mato Grosso do Sul & 0,101 & 27 & Piauí & 0,196 & 27 \\
\hline
\end{tabular}

Fonte: Elaboração própria.

Entre os anos de 2002 e 2008, o Acre subiu sete posições, passando do décimo lugar no ranking para o terceiro. Esse comportamento pode ser justificado pelo elevado nível de investimento em capital humano per capita em 2008 (R \$ 1.002) e pelos maiores gastos per capita com pesquisa e desenvolvimento ( $\mathrm{R} \$ 19,9)$. Em relação ao estado de São Paulo, verificou-se uma queda de colocação, da terceira 
para a nona. A redução significativa dos gastos com pesquisa e desenvolvimento (de $\mathrm{R} \$ 24,9$ em 2002 para $\mathrm{R} \$ 6,9$ em 2008) foi o que determinou o pior desempenho do estado de acordo com essa dimensão. Apresentando a maior queda de colocações entre os estados, Pernambuco saiu do quinto lugar no ranking para o $23^{\circ}$. Em três dos quatro indicadores o estado exibiu queda de desempenho, sobretudo em relação ao capital físico per capita, em que era o quarto no ranking em 2002 e foi para a $19^{\text {a }}$ colocação em 2008. É possível observar ainda a melhora de posicionamento para o estado de Goiás, que saiu da $26^{\mathrm{a}}$ colocação para a décima, nomeadamente devido aos maiores gastos per capita com pesquisa e desenvolvimento. Por fim, verificou-se que o Rio Grande do Sul caiu nove posições, o que pode ser explicado pela piora em três indicadores: capital humano, pesquisa e desenvolvimento e dívida pública.

Os valores da dimensão "Equidade", assim como o ranqueamento entre os estados, estão expostos na Tabela 3.

Tabela 3 - Valores da dimensão "Equidade" e ranqueamento segundo as unidades da federação (2002 e 2008)

\begin{tabular}{lcclcc}
\hline \multicolumn{1}{c}{ Estado } & $\mathbf{2 0 0 2}$ & Posição & \multicolumn{1}{c}{ Estado } & $\mathbf{2 0 0 8}$ & Posição \\
\hline Santa Catarina & 0,972 & 1 & Santa Catarina & 0,958 & 1 \\
Rio Grande do Sul & 0,757 & 2 & Rio Grande do Sul & 0,835 & 2 \\
Paraná & 0,723 & 3 & São Paulo & 0,779 & 3 \\
Rio de Janeiro & 0,686 & 4 & Paraná & 0,751 & 4 \\
Goiás & 0,656 & 5 & Minas Gerais & 0,709 & 5 \\
São Paulo & 0,652 & 6 & Goiás & 0,688 & 6 \\
Mato Grosso do Sul & 0,621 & 7 & Mato Grosso do Sul & 0,631 & 7 \\
Rondônia & 0,608 & 8 & Espírito Santo & 0,622 & 8 \\
Minas Gerais & 0,594 & 9 & Amapá & 0,612 & 9 \\
Tocantins & 0,535 & 10 & Rio de Janeiro & 0,594 & 10 \\
Sergipe & 0,494 & 11 & Roraima & 0,530 & 11 \\
Espírito Santo & 0,486 & 12 & Tocantins & 0,525 & 12 \\
Mato Grosso & 0,448 & 13 & Rondônia & 0,501 & 13 \\
Pará & 0,445 & 14 & Pará & 0,480 & 14 \\
Acre & 0,386 & 15 & Mato Grosso & 0,480 & 15 \\
Distrito Federal & 0,380 & 16 & Ceará & 0,422 & 16 \\
Roraima & 0,348 & 17 & Rio Grande do Norte & 0,391 & 17 \\
Ceará & 0,334 & 18 & Sergipe & 0,380 & 18 \\
Rio Grande do Norte & 0,333 & 19 & Bahia & 0,334 & 19 \\
Bahia & 0,293 & 20 & Amazonas & 0,322 & 20 \\
\hline & & & & & continua...
\end{tabular}


conclusão.

\begin{tabular}{|c|c|c|c|c|c|}
\hline Estado & 2002 & Posição & Estado & 2008 & Posição \\
\hline Amazonas & 0,288 & 21 & Piauí & 0,321 & 21 \\
\hline Paraíba & 0,286 & 22 & Distrito Federal & 0,319 & 22 \\
\hline Maranhão & 0,275 & 23 & Acre & 0,311 & 23 \\
\hline Pernambuco & 0,252 & 24 & Maranhão & 0,304 & 24 \\
\hline Amapá & 0,252 & 25 & Pernambuco & 0,279 & 25 \\
\hline Piauí & 0,175 & 26 & Paraíba & 0,272 & 26 \\
\hline Alagoas & 0,131 & 27 & Alagoas & 0,122 & 27 \\
\hline
\end{tabular}

Fonte: Elaboração própria.

A dimensão "Equidade", que é composta pelos indicadores desigualdade de renda e intensidade da pobreza, teve em 2002 os estados de Santa Catarina, Rio Grande do Sul, Paraná e Rio de Janeiro como aqueles que apresentaram o melhor desempenho. Por outro lado, no mesmo ano, Pernambuco, Amapá, Piauí e Alagoas foram os quatro piores estados em relação aos indicadores considerados. Em 2008, Santa Catarina permaneceu como o estado mais bem colocado entre todas as unidades da federação, seguido pelo Rio Grande do Sul, São Paulo e Paraná. Por meio dos resultados obtidos, foi possível observar que Rio de Janeiro, Distrito Federal, Sergipe e Acre tiveram uma queda de posicionamento no ranking entre 2002 e 2008. O motivo dessa queda para os três primeiros estados foram as reduções nos dois indicadores de equidade, enquanto o Acre apresentou piora apenas no indicador intensidade da pobreza.

Ainda em relação à dimensão analisada, é importante destacar o elevado grau de desigualdade de renda verificado no Distrito Federal. Dentre todas as unidades da federação, ele é o que possui a maior desigualdade de distribuição de renda, o que acaba por influenciar em sua colocação na dimensão equidade.

A Tabela 4 apresenta os resultados da dimensão "Seguridade Econômica", compreendida pelos seguintes indicadores: risco de desemprego, risco financeiro associado à doença, risco de pobreza em idade avançada e risco de violência. Em 2002, os quatro melhores estados segundo essa dimensão foram o Piauí, o Maranhão, o Rio Grande do Norte e a Paraíba, todos pertencentes à região Nordeste. Os bons resultados se deram em decorrência dos baixos valores apresentados para os indicadores de risco, sobretudo para o risco de pobreza em idade avançada e para o risco de violência, medida pela taxa de homicídios. Uma possível justificativa para o baixo risco de pobreza em idade avançada é a grande participação de idosos em programas de transferência do governo federal como o Benefício de Prestação Continuada (BPC), destinado aos idosos com 65 anos ou mais e às pessoas com deficiências não aptas a trabalhar e que possuem renda per capita familiar abaixo de um quarto do salário mínimo vigente. Cabe destacar ainda que 
a região Nordeste é a maior beneficiada desde o início do Programa em 1996, com $49 \%$ do total de benefícios (BRASIL, 2010).

Tabela 4 - Valores da dimensão "Seguridade econômica" e ranqueamento segundo as unidades da federação (2002 e 2008)

\begin{tabular}{|c|c|c|c|c|c|}
\hline Estado & 2002 & Posição & Estado & 2008 & Posição \\
\hline Piauí & 0,970 & 1 & Piauí & 0,900 & 1 \\
\hline Maranhão & 0,949 & 2 & Ceará & 0,839 & 2 \\
\hline Rio Grande do Norte & 0,918 & 3 & Maranhão & 0,832 & 3 \\
\hline Paraíba & 0,884 & 4 & Tocantins & 0,826 & 4 \\
\hline Santa Catarina & 0,854 & 5 & Santa Catarina & 0,786 & 5 \\
\hline Ceará & 0,833 & 6 & Paraíba & 0,780 & 6 \\
\hline Bahia & 0,804 & 7 & Rio Grande do Norte & 0,765 & 7 \\
\hline Pará & 0,789 & 8 & Pará & 0,759 & 8 \\
\hline Acre & 0,786 & 9 & Rio Grande do Sul & 0,702 & 9 \\
\hline Rio Grande do Sul & 0,777 & 10 & Acre & 0,676 & 10 \\
\hline Tocantins & 0,774 & 11 & Minas Gerais & 0,670 & 11 \\
\hline Paraná & 0,752 & 12 & Goiás & 0,651 & 12 \\
\hline Alagoas & 0,751 & 13 & Paraná & 0,643 & 13 \\
\hline Minas Gerais & 0,745 & 14 & Sergipe & 0,639 & 14 \\
\hline Goiás & 0,739 & 15 & Roraima & 0,639 & 15 \\
\hline Sergipe & 0,716 & 16 & Rondônia & 0,625 & 16 \\
\hline Mato Grosso do Sul & 0,707 & 17 & Bahia & 0,622 & 17 \\
\hline Amazonas & 0,695 & 18 & Mato Grosso do Sul & 0,606 & 18 \\
\hline Rondônia & 0,679 & 19 & Mato Grosso & 0,591 & 19 \\
\hline Mato Grosso & 0,644 & 20 & Alagoas & 0,569 & 20 \\
\hline Espírito Santo & 0,579 & 21 & Amazonas & 0,539 & 21 \\
\hline Pernambuco & 0,575 & 22 & Pernambuco & 0,496 & 22 \\
\hline Roraima & 0,553 & 23 & Espírito Santo & 0,475 & 23 \\
\hline São Paulo & 0,492 & 24 & São Paulo & 0,468 & 24 \\
\hline Rio de Janeiro & 0,417 & 25 & Amapá & 0,350 & 25 \\
\hline Distrito Federal & 0,413 & 26 & Rio de Janeiro & 0,295 & 26 \\
\hline Amapá & 0,400 & 27 & Distrito Federal & 0,272 & 27 \\
\hline
\end{tabular}

Fonte: Elaboração própria.

A análise do ano de 2008 permite verificar que dois dos quatro melhores estados em 2002 se mantiveram em boas colocações em 2008, sendo acompanhados pelo Ceará e Tocantins. Deve-se salientar que Tocantins exibiu o menor risco 
de pobreza em idade avançada em 2008, uma vez que apenas $2,4 \%$ das pessoas com 65 anos ou mais estavam abaixo da linha da pobreza naquele ano. De modo análogo, o Ceará obteve o segundo menor risco associado à doença, o que contribuiu para sua elevação em quatro colocações no ranking da dimensão. O Piauí, primeiro colocado nos dois anos da análise, apresentou o terceiro menor risco de desemprego em 2002 e 2008, o menor risco de pobreza em idade avançada em 2002 e o segundo menor em 2008 , e ainda o segundo menor risco de violência em 2002 e o terceiro menor em 2008.

Além disso, foi possível observar que, tanto em 2002 quanto em 2008, os estados de São Paulo, Rio de Janeiro, Distrito Federal e Amapá foram os que obtiveram os piores desempenhos. Em relação ao indicador risco de desemprego, o Amapá foi aquele que teve o mais elevado valor, seguido pelo Distrito Federal. Outro destaque é para o indicador risco financeiro associado à doença, em que o Distrito Federal tem o mais elevado valor, acompanhado por Rio de Janeiro e São Paulo.

Em relação ao indicador risco de violência, tem-se que os piores estados foram, em 2008, Alagoas, Espírito Santo e Pernambuco. Foi esse o indicador responsável pela queda de sete posições do estado de Alagoas, o qual apresentou elevação de aproximadamente 74\% na taxa de homicídios entre 2002 e 2008.

\subsection{O IBEE segundo as Unidades da Federação Brasileira}

O IBEE construído a partir das quatro dimensões analisadas anteriormente, utilizando ponderações uniformes entre cada uma das dimensões, é reportado na Tabela 5. O estado mais bem colocado nos dois anos da análise foi Santa Catarina, com IBEE igual a 0,665 em 2002 e 0,703 em 2008. É importante enfatizar que o estado se destacou em todas as dimensões do índice, sobretudo em equidade, onde foram analisadas a distribuição de renda e a pobreza. Dessa forma, tem-se que a melhor localidade em termos de bem-estar econômico, considerando que todas as dimensões do índice possuem igual contribuição para o mesmo, é Santa Catarina.

A melhora em três posições no ranking, devido ao bom posicionamento nas dimensões fluxos de consumo e equidade, fez com que São Paulo fosse o segundo melhor estado do Brasil, no ano de 2008, em bem-estar econômico. O IBEE elevou-se de 0,566 em 2002 para 0,608 em 2008. Os estados do Rio Grande do Sul e do Paraná também estiveram entre os quatro primeiros colocados nos anos analisados, demonstrando que os recursos disponíveis na Região Sul possibilitam aos seus habitantes uma melhor qualidade de vida em relação aos demais estados.

Os estados que obtiveram as piores colocações em 2002 foram: Alagoas, Piauí, Pernambuco e Paraíba, todos pertencentes à Região Nordeste. O estado 
de Alagoas, que apresentou o pior IBEE nos dois anos da análise (0,291 em 2002 e 0,239 em 2008), esteve mal posicionado no ranking de todas as dimensões do índice, nomeadamente na dimensão equidade, em que apareceu em último lugar em 2002 e em 2008. Cabe destacar que, tanto em 2002 quanto em 2008, o estado exibiu o segundo maior índice de intensidade da pobreza (FGT) e um dos mais elevados índices de Gini (0,61 em 2002 e 0,58 em 2008).

Os estados com menores índices de bem-estar econômico em 2008 foram, novamente, aqueles pertencentes à Região Nordeste - Alagoas, Pernambuco, Paraíba e Bahia. Embora seis anos tenham se passado entre o primeiro e o último ano da análise, os estados dessa região permaneceram como sendo aqueles de menor qualidade de vida em termos econômicos.

Afora isto, é necessário chamar a atenção para as variações no ranking observadas no Distrito Federal, no Rio de Janeiro, em Roraima e no Amapá. O Distrito Federal saiu da segunda colocação em 2002 (IBEE igual a 0,612) para a oitava posição em 2008 (IBEE de 0,545), tendo como principal determinante a piora no indicador de pobreza. De modo semelhante, o Rio de Janeiro apresentou uma redução de seis colocações no ranking do IBEE, sobretudo devido à elevação tanto da pobreza quanto da desigualdade.

Tabela 5 - Índice de Bem-Estar Econômico e ranqueamento segundo as unidades da federação - pesos iguais (2002 e 2008)

\begin{tabular}{lcclcc}
\hline \multicolumn{1}{c}{ Estado } & $\mathbf{2 0 0 2}$ & Posição & \multicolumn{1}{c}{ Estado } & $\mathbf{2 0 0 8}$ & Posição \\
\hline Santa Catarina & 0,665 & 1 & Santa Catarina & 0,703 & 1 \\
Distrito Federal & 0,612 & 2 & São Paulo & 0,608 & 2 \\
Paraná & 0,611 & 3 & Rio Grande do Sul & 0,592 & 3 \\
Rio Grande do Sul & 0,576 & 4 & Paraná & 0,591 & 4 \\
São Paulo & 0,566 & 5 & Minas Gerais & 0,578 & 5 \\
Minas Gerais & 0,519 & 6 & Tocantins & 0,553 & 6 \\
Acre & 0,486 & 7 & Goiás & 0,549 & 7 \\
Rio de Janeiro & 0,484 & 8 & Distrito Federal & 0,545 & 8 \\
Tocantins & 0,465 & 9 & Roraima & 0,544 & 9 \\
Espírito Santo & 0,462 & 10 & Espírito Santo & 0,543 & 10 \\
Goiás & 0,454 & 11 & Acre & 0,526 & 11 \\
Pará & 0,454 & 12 & Amapá & 0,512 & 12 \\
Sergipe & 0,441 & 13 & Mato Grosso do Sul & 0,498 & 13 \\
Rondônia & 0,435 & 14 & Rio de Janeiro & 0,476 & 14 \\
Mato Grosso do Sul & 0,427 & 15 & Pará & 0,475 & 15 \\
Rio Grande do Norte & 0,423 & 16 & Mato Grosso & 0,459 & 16 \\
\hline & & & & & continua...
\end{tabular}


conclusão.

\begin{tabular}{lcclcc}
\hline \multicolumn{1}{c}{ Estado } & $\mathbf{2 0 0 2}$ & Posição & \multicolumn{1}{c}{ Estado } & $\mathbf{2 0 0 8}$ & Posição \\
\hline Maranhão & 0,414 & 17 & Rondônia & 0,458 & 17 \\
Ceará & 0,400 & 18 & Sergipe & 0,438 & 18 \\
Mato Grosso & 0,395 & 19 & Rio Grande do Norte & 0,424 & 19 \\
Roraima & 0,391 & 20 & Ceará & 0,412 & 20 \\
Amapá & 0,370 & 21 & Maranhão & 0,396 & 21 \\
Amazonas & 0,370 & 22 & Amazonas & 0,396 & 22 \\
Bahia & 0,368 & 23 & Piauí & 0,382 & 23 \\
Paraíba & 0,368 & 24 & Bahia & 0,375 & 24 \\
Pernambuco & 0,366 & 25 & Paraíba & 0,368 & 25 \\
Piauí & 0,351 & 26 & Pernambuco & 0,319 & 26 \\
Alagoas & 0,291 & 27 & Alagoas & 0,239 & 27 \\
\hline
\end{tabular}

Fonte: Elaboração própria.

Ademais, verificou-se um aumento no IBEE de Roraima em 39\%, o que lhe conferiu a nona colocação em 2008. De modo análogo, o Amapá subiu nove posições de 2002 para 2008, demonstrando uma melhora em termos de bem-estar econômico em relação aos demais estados.

No intuito de evitar arbitrariedades em relação à atribuição de pesos a cada um dos indicadores, o IBEE foi calculado de outras quatro maneiras distintas, assumindo ponderações diferentes em cada uma delas.

A Tabela 6 apresenta o IBEE e o ranqueamento dos estados ao considerar a ponderação de 0,4 para a dimensão "Fluxos de Consumo" e 0,2 para cada uma das demais dimensões. Ao ser dado maior peso para a dimensão composta por consumo público per capita e consumo privado per capita, são favorecidos aqueles estados que obtiveram maiores valores para esses indicadores. Dessa forma, tem-se nos dois anos da análise o Distrito Federal, Santa Catarina, Paraná, São Paulo e Rio Grande do Sul como os estados de mais elevado IBEE. Semelhantemente ao IBEE calculado com ponderações uniformes, os estados em pior situação foram aqueles situados na Região Nordeste.

Os resultados demonstram ainda uma melhora no IBEE de Roraima e Amapá, os quais saíram da $15^{\mathrm{a}}$ posição para a sétima e da $18^{\mathrm{a}}$ colocação para a $11^{\mathrm{a}}$, respectivamente. A elevação no ranking foi devida ao maior consumo público per capita observado em 2008, algo também refletido na melhora de posicionamento na dimensão "Fluxos de Consumo".

Cabe salientar ainda que, mesmo atribuindo maior peso para os indicadores de consumo público e privado, o estado de Santa Catarina se manteve como sendo aquele que apresenta melhores condições de bem-estar econômico, ao 
passo que Alagoas permanece como o estado em que se têm os piores níveis de bem-estar.

Tabela 6 - Índice de Bem-Estar Econômico e ranqueamento segundo as unidades da federação - maior peso para a dimensão "Fluxos de consumo" (2002 e 2008)

\begin{tabular}{|c|c|c|c|c|c|}
\hline Estado & 2002 & Posição & Estado & 2008 & Posição \\
\hline Distrito Federal & 0,690 & 1 & Santa Catarina & 0,674 & 1 \\
\hline Santa Catarina & 0,608 & 2 & São Paulo & 0,627 & 2 \\
\hline Paraná & 0,555 & 3 & Distrito Federal & 0,625 & 3 \\
\hline São Paulo & 0,554 & 4 & Rio Grande do Sul & 0,582 & 4 \\
\hline Rio Grande do Sul & 0,547 & 5 & Paraná & 0,554 & 5 \\
\hline Rio de Janeiro & 0,496 & 6 & Espírito Santo & 0,546 & 6 \\
\hline Minas Gerais & 0,470 & 7 & Roraima & 0,544 & 7 \\
\hline Acre & 0,455 & 8 & Minas Gerais & 0,543 & 8 \\
\hline Espírito Santo & 0,435 & 9 & Acre & 0,532 & 9 \\
\hline Tocantins & 0,423 & 10 & Tocantins & 0,530 & 10 \\
\hline Goiás & 0,411 & 11 & Amapá & 0,524 & 11 \\
\hline Mato Grosso do Sul & 0,397 & 12 & Rio de Janeiro & 0,516 & 12 \\
\hline Rondônia & 0,396 & 13 & Goiás & 0,514 & 13 \\
\hline Sergipe & 0,386 & 14 & Mato Grosso do Sul & 0,503 & 14 \\
\hline Roraima & 0,378 & 15 & Rondônia & 0,453 & 15 \\
\hline Pará & 0,377 & 16 & Mato Grosso & 0,448 & 16 \\
\hline Mato Grosso & 0,370 & 17 & Pará & 0,404 & 17 \\
\hline Amapá & 0,362 & 18 & Sergipe & 0,401 & 18 \\
\hline Rio Grande do Norte & 0,362 & 19 & Rio Grande do Norte & 0,378 & 19 \\
\hline Ceará & 0,343 & 20 & Amazonas & 0,367 & 20 \\
\hline Amazonas & 0,333 & 21 & Ceará & 0,342 & 21 \\
\hline Maranhão & 0,331 & 22 & Bahia & 0,335 & 22 \\
\hline Bahia & 0,321 & 23 & Piauí & 0,327 & 23 \\
\hline Pernambuco & 0,321 & 24 & Paraíba & 0,323 & 24 \\
\hline Paraíba & 0,305 & 25 & Maranhão & 0,322 & 25 \\
\hline Piauí & 0,290 & 26 & Pernambuco & 0,293 & 26 \\
\hline Alagoas & 0,246 & 27 & Alagoas & 0,200 & 27 \\
\hline
\end{tabular}

Fonte: Elaboração própria.

O IBEE calculado a partir da maior ponderação para a dimensão "Riqueza Real - Legado Intergeracional", assim como o ranqueamento entre os estados, encontra-se na Tabela 7. É possível observar que, novamente, Santa Catarina des- 
taca-se como a localidade de mais elevado $\operatorname{IBEE}(0,623$ em 2002 e 0,665 em 2008), demonstrando que há no estado uma boa qualidade de vida em termos econômicos, independentemente da ponderação dada a cada dimensão. No entanto, é necessário enfatizar que o IBEE é um índice que varia de zero à unidade, sendo ainda preciso certos avanços em relação aos indicadores analisados para que sejam verificados melhores níveis de bem-estar econômico. Não obstante, observa-se que o estado de Alagoas encontra-se mais uma vez como o pior colocado em relação ao bem-estar econômico, com IBEE igual a 0,275 em 2002 e 0,235 em 2008 .

Os estados que mais sofreram alterações em termos do indicador de um ano para o outro foram Maranhão, Pernambuco, Goiás e Roraima. Em relação aos dois primeiros, tem-se uma queda de oito e nove posições, respectivamente. A redução no IBEE do Maranhão para 0,401, em 2008, deve-se especialmente à menor elevação do investimento em pesquisa e desenvolvimento em relação aos demais estados. O estado de Pernambuco, conforme já ressaltado anteriormente, teve uma piora relativa em três dos quatro indicadores que compõem a dimensão "Riqueza Real - Legado Intergeracional", sobretudo referente ao capital físico, em que se tinha $R \$ 1,11$ de investimento per capita em 2002, passando para $R \$ 0,32$ per capita em 2008. De modo inverso, Goiás e Roraima desfrutaram de elevações no ranqueamento do IBEE de um ano da análise para o outro. O primeiro devido às maiores despesas per capita com pesquisa e desenvolvimento $(\mathrm{R} \$ 1,19 \mathrm{em} 2002$ para $R \$ 24,07$ em 2008), e o segundo por causa da redução da dívida pública per capita ( $\mathrm{R} \$ 1,26$ para $-\mathrm{R} \$ 0,49)$.

Tabela 7 - Índice de Bem-Estar Econômico e ranqueamento segundo as unidades da federação - maior peso para a dimensão "Riqueza real - Legado intergeracional" (2002 e 2008)

\begin{tabular}{lcclcc}
\hline \multicolumn{1}{c}{ Estado } & $\mathbf{2 0 0 2}$ & Posição & \multicolumn{1}{c}{ Estado } & $\mathbf{2 0 0 8}$ & Posição \\
\hline Santa Catarina & 0,623 & 1 & Santa Catarina & 0,665 & 1 \\
Distrito Federal & 0,621 & 2 & Paraná & 0,586 & 2 \\
Paraná & 0,616 & 3 & São Paulo & 0,584 & 3 \\
São Paulo & 0,576 & 4 & Minas Gerais & 0,569 & 4 \\
Rio Grande do Sul & 0,528 & 5 & Distrito Federal & 0,566 & 5 \\
Minas Gerais & 0,508 & 6 & Espírito Santo & 0,538 & 6 \\
Acre & 0,476 & 7 & Goiás & 0,536 & 7 \\
Pará & 0,466 & 8 & Acre & 0,532 & 8 \\
Espírito Santo & 0,460 & 9 & Rio Grande do Sul & 0,531 & 9 \\
Rio de Janeiro & 0,446 & 10 & Roraima & 0,529 & 10 \\
Tocantins & 0,431 & 11 & Tocantins & 0,528 & 11 \\
Sergipe & 0,430 & 12 & Amapá & 0,513 & 12 \\
\hline
\end{tabular}


conclusão.

\begin{tabular}{lcclcc}
\hline \multicolumn{1}{c}{ Estado } & $\mathbf{2 0 0 2}$ & Posição & \multicolumn{1}{c}{ Estado } & $\mathbf{2 0 0 8}$ & Posição \\
\hline Maranhão & 0,417 & 13 & Pará & 0,488 & 13 \\
Rio Grande do Norte & 0,403 & 14 & Rio de Janeiro & 0,449 & 14 \\
Goiás & 0,400 & 15 & Sergipe & 0,445 & 15 \\
Amapá & 0,395 & 16 & Mato Grosso do Sul & 0,445 & 16 \\
Pernambuco & 0,393 & 17 & Mato Grosso & 0,439 & 17 \\
Rondônia & 0,390 & 18 & Rondônia & 0,420 & 18 \\
Ceará & 0,384 & 19 & Amazonas & 0,410 & 19 \\
Roraima & 0,380 & 20 & Rio Grande do Norte & 0,407 & 20 \\
Mato Grosso do Sul & 0,362 & 21 & Maranhão & 0,401 & 21 \\
Mato Grosso & 0,359 & 22 & Ceará & 0,395 & 22 \\
Amazonas & 0,357 & 23 & Bahia & 0,374 & 23 \\
Paraíba & 0,345 & 24 & Paraíba & 0,349 & 24 \\
Bahia & 0,344 & 25 & Piauí & 0,345 & 25 \\
Piauí & 0,322 & 26 & Pernambuco & 0,317 & 26 \\
Alagoas & 0,275 & 27 & Alagoas & 0,235 & 27 \\
\hline
\end{tabular}

Fonte: Elaboração própria.

O cálculo do IBEE atribuindo maior peso para a dimensão "Equidade" fez com que o índice para o estado de Santa Catarina ficasse ainda mais elevado $(0,727$ em 2002 e 0,754 em 2008) em relação às demais formas de ponderação (Tabela 8). No ano de 2002, os estados que apresentaram os maiores IBEEs além de Santa Catarina, foram o Paraná, o Rio Grande do Sul e São Paulo. Em 2008, São Paulo e Paraná trocaram de colocações, mas permaneceram entre os quatro mais bem colocados no ranking, juntamente ao Rio Grande do Sul e Santa Catarina. A atribuição de maior peso para os indicadores de pobreza e distribuição de renda fez com que todos os estados da Região Sul estivessem entre os quatro melhores estados, em termos de bem-estar econômico, nos dois anos da análise. Por outro lado, é possível observar que os estados em pior situação estão na Região Nordeste, com destaque para Alagoas que, novamente, apresenta o mais baixo IBEE $(0,259 \mathrm{em} 2002$ e $0,216 \mathrm{em} 2008)$. Com o segundo pior indicador de intensidade de pobreza em 2002 e 2008 e com índices de desigualdade de distribuição de renda bastante elevados, o estado de Alagoas tem se mostrado como aquele de mais reduzido bem-estar econômico, independentemente da ponderação estabelecida para cada dimensão do IBEE.

Os resultados demonstram ainda uma grande variação no ranqueamento sofrida por Roraima e Amapá entre os anos abrangidos pelo estudo. O estado de Roraima, que saiu da $20^{\mathrm{a}}$ colocação para a nona, sofreu uma redução de $23 \%$ no 
índice FGT de intensidade de pobreza. O Amapá, por sua vez, apresentou o mais reduzido nível de desigualdade de distribuição de renda em $2008(0,451)$, sendo o primeiro no ranking do índice de Gini, o que contribuiu para que saísse da $24^{\mathrm{a}}$ posição e fosse para a $10^{\mathrm{a}}$.

Tabela 8 - Índice de Bem-Estar Econômico e ranqueamento segundo as unidades da federação - maior peso para a dimensão "Equidade" (2002 e 2008)

\begin{tabular}{|c|c|c|c|c|c|}
\hline Estado & 2002 & Posição & Estado & 2008 & Posição \\
\hline Santa Catarina & 0,727 & 1 & Santa Catarina & 0,754 & 1 \\
\hline Paraná & 0,633 & 2 & São Paulo & 0,642 & 2 \\
\hline Rio Grande do Sul & 0,612 & 3 & Rio Grande do Sul & 0,641 & 3 \\
\hline São Paulo & 0,583 & 4 & Paraná & 0,623 & 4 \\
\hline Distrito Federal & 0,566 & 5 & Minas Gerais & 0,604 & 5 \\
\hline Minas Gerais & 0,534 & 6 & Goiás & 0,577 & 6 \\
\hline Rio de Janeiro & 0,525 & 7 & Espírito Santo & 0,559 & 7 \\
\hline Goiás & 0,494 & 8 & Tocantins & 0,548 & 8 \\
\hline Tocantins & 0,479 & 9 & Roraima & 0,541 & 9 \\
\hline Rondônia & 0,469 & 10 & Amapá & 0,532 & 10 \\
\hline Espírito Santo & 0,467 & 11 & Mato Grosso do Sul & 0,525 & 11 \\
\hline Acre & 0,466 & 12 & Distrito Federal & 0,500 & 12 \\
\hline Mato Grosso do Sul & 0,466 & 13 & Rio de Janeiro & 0,500 & 13 \\
\hline Pará & 0,452 & 14 & Acre & 0,483 & 14 \\
\hline Sergipe & 0,451 & 15 & Pará & 0,476 & 15 \\
\hline Mato Grosso & 0,405 & 16 & Rondônia & 0,466 & 16 \\
\hline Rio Grande do Norte & 0,405 & 17 & Mato Grosso & 0,463 & 17 \\
\hline Ceará & 0,387 & 18 & Sergipe & 0,426 & 18 \\
\hline Maranhão & 0,386 & 19 & Rio Grande do Norte & 0,417 & 19 \\
\hline Roraima & 0,382 & 20 & Ceará & 0,414 & 20 \\
\hline Bahia & 0,353 & 21 & Amazonas & 0,381 & 21 \\
\hline Amazonas & 0,353 & 22 & Maranhão & 0,378 & 22 \\
\hline Paraíba & 0,352 & 23 & Piauí & 0,369 & 23 \\
\hline Amapá & 0,346 & 24 & Bahia & 0,367 & 24 \\
\hline Pernambuco & 0,343 & 25 & Paraíba & 0,348 & 25 \\
\hline Piauí & 0,316 & 26 & Pernambuco & 0,311 & 26 \\
\hline Alagoas & 0,259 & 27 & Alagoas & 0,216 & 27 \\
\hline
\end{tabular}

Fonte: Elaboração própria. 
Os valores do IBEE e o ranqueamento dos estados obtidos a partir da maior ponderação para a dimensão "Seguridade Econômica" são apresentados na Tabela 9. No ano de 2002, os estados de Santa Catarina, Paraná, Rio Grande do Sul e Distrito Federal foram aqueles que alcançaram as quatro primeiras colocações no ranking do IBEE. Por outro lado, Amapá, Alagoas, Pernambuco e Roraima obtiveram os mais baixos índices. O IBEE calculado para 2008 demonstra que, mais uma vez, os indivíduos da Região Sul são aqueles que usufruem de maior bem-estar econômico em comparação aos que residem nas demais regiões brasileiras.

Uma grande variabilidade no ranqueamento dos estados pôde ainda ser observada, sobretudo para o Distrito Federal, Tocantins, Sergipe, Roraima e Amapá. A queda de colocação sofrida pelo Distrito Federal (quarto lugar para o $16^{\circ}$ ) deve-se, sobretudo, ao maior risco de pobreza em idade avançada e pelo elevado risco de violência. É importante salientar que a referida unidade da federação foi aquela que apresentou o mais alto risco financeiro associado à doença e o segundo maior risco de desemprego nos anos analisados (14,2\% em 2002 e 11,2\% em 2008).

O estado do Tocantins saiu da oitava colocação no ranking para a terceira devido ao baixo risco de pobreza em idade avançada e ao baixo risco de violência. Em 2008, o estado obteve o menor risco de pobreza entre pessoas com 65 anos ou mais, uma vez que apenas $2,4 \%$ da população pertencente a essa faixa etária recebia menos de meio salário mínimo. Esse mesmo indicador foi o responsável pela queda de oito colocações de Sergipe, que saiu do $13^{\circ}$ lugar para o $21^{\circ}$. Ainda que o percentual de idosos pobres no estado não tenha variado significativamente de um ano para o outro, em comparação aos demais estados, o percentual permaneceu bastante elevado, fazendo com que o IBEE fosse de apenas 0,478. 
Tabela 9 - Índice de Bem-Estar Econômico e ranqueamento segundo as unidades da federação - maior peso para a dimensão "Seguridade econômica" (2002 e 2008)

\begin{tabular}{|c|c|c|c|c|c|}
\hline Estado & 2002 & Posição & Estado & 2008 & Posição \\
\hline Santa Catarina & 0,703 & 1 & Santa Catarina & 0,720 & 1 \\
\hline Paraná & 0,639 & 2 & Rio Grande do Sul & 0,614 & 2 \\
\hline Rio Grande do Sul & 0,616 & 3 & Tocantins & 0,608 & 3 \\
\hline Distrito Federal & 0,572 & 4 & Paraná & 0,602 & 4 \\
\hline Minas Gerais & 0,564 & 5 & Minas Gerais & 0,597 & 5 \\
\hline São Paulo & 0,551 & 6 & São Paulo & 0,580 & 6 \\
\hline Acre & 0,546 & 7 & Goiás & 0,570 & 7 \\
\hline Tocantins & 0,527 & 8 & Roraima & 0,563 & 8 \\
\hline Rio Grande do Norte & 0,522 & 9 & Acre & 0,556 & 9 \\
\hline Pará & 0,521 & 10 & Pará & 0,532 & 10 \\
\hline Maranhão & 0,521 & 11 & Espírito Santo & 0,529 & 11 \\
\hline Goiás & 0,511 & 12 & Mato Grosso do Sul & 0,520 & 12 \\
\hline Sergipe & 0,496 & 13 & Ceará & 0,498 & 13 \\
\hline Ceará & 0,487 & 14 & Rio Grande do Norte & 0,492 & 14 \\
\hline Espírito Santo & 0,485 & 15 & Rondônia & 0,491 & 15 \\
\hline Rondônia & 0,484 & 16 & Distrito Federal & 0,491 & 16 \\
\hline Mato Grosso do Sul & 0,483 & 17 & Mato Grosso & 0,485 & 17 \\
\hline Piauí & 0,474 & 18 & Piauí & 0,485 & 18 \\
\hline Paraíba & 0,471 & 19 & Maranhão & 0,483 & 19 \\
\hline Rio de Janeiro & 0,471 & 20 & Amapá & 0,480 & 20 \\
\hline Bahia & 0,456 & 21 & Sergipe & 0,478 & 21 \\
\hline Mato Grosso & 0,444 & 22 & Paraíba & 0,450 & 22 \\
\hline Amazonas & 0,435 & 23 & Rio de Janeiro & 0,440 & 23 \\
\hline Roraima & 0,423 & 24 & Bahia & 0,425 & 24 \\
\hline Pernambuco & 0,408 & 25 & Amazonas & 0,424 & 25 \\
\hline Alagoas & 0,383 & 26 & Pernambuco & 0,354 & 26 \\
\hline Amapá & 0,376 & 27 & Alagoas & 0,305 & 27 \\
\hline
\end{tabular}

Fonte: Elaboração própria.

A queda no risco de pobreza em idade avançada e no risco de violência também foi a responsável pela melhora de posicionamento dos estados de Roraima e Amapá. Apresentando a maior incidência de pobreza entre pessoas com 65 anos ou mais em 2002, o estado de Roraima conseguiu melhorar expressivamente esse indicador, saindo de um percentual de 21,3\% para apenas 5,53\%. De modo seme- 
lhante, no entanto menos expressiva, a queda no risco de pobreza entre idosos fez com que o Amapá saísse da última colocação no ranking em 2002 e alcançasse um IBEE de 0,480 em 2008. Ademais, o risco de violência em ambos os estados foi reduzido em $23 \%$, contribuindo para que a melhora de bem-estar fosse ainda mais acentuada.

Embora em nenhuma das formas de cálculo do IBEE o Rio de Janeiro tenha estado entre aqueles de mais elevado índice de bem-estar econômico, a maior ponderação para a dimensão "Seguridade Econômica" fez com que o estado estivesse na $20^{a}$ colocação em 2002 e caísse ainda mais em 2008 , ocupando a $23^{\text {a }}$ posição do ranking. Pertencente ao grupo de estados com maior inseguridade econômica, o Rio de Janeiro apresentou péssimos indicadores de risco, sobretudo de pobreza em idade avançada, o que colaborou para que obtivesse um IBEE de apenas $0,440 \mathrm{em} 2008$.

Os resultados das cinco especificações para as ponderações se mostraram semelhantes em termos de ranqueamento dos estados. Dessa forma, acredita-se na robustez dos resultados quanto à utilização de diferentes atribuições de pesos. No entanto, deve-se ressaltar a facilidade em operacionalizar um indicador a partir de ponderações uniformes, não implicando em maiores julgamentos de valor no momento da imputação de pesos. Além disso, a utilização de pesos iguais não favorece uma localidade que tenha uma determinada dimensão mais elevada em relação às demais.

\section{Considerações Finais}

O presente estudo teve como objetivo geral a construção de um Índice de Bem-Estar Econômico (IBEE) para os estados brasileiros. Especificamente, buscou-se verificar os níveis de bem-estar econômico e de seus subcomponentes nos anos de 2002 e 2008, além de compará-los entre os estados.

O índice proposto foi composto por quatro dimensões distintas: "Fluxos de Consumo", obtida pelos indicadores de consumo privado e consumo público; "Riqueza Real - Legado Intergeracional", resultante dos indicadores capital físico, capital humano, gastos com pesquisa e desenvolvimento e débito público; "Equidade", construída a partir do Índice de Gini e do Índice FGT; e "Seguridade Econômica”, formada pelos indicadores de risco de desemprego, risco financeiro associado à doença, risco de pobreza em idade avançada e risco de violência.

A análise teve início com o ranqueamento das unidades da federação brasileira segundo cada uma das dimensões do IBEE. Os resultados demonstraram que, de acordo com a dimensão "Fluxos de Consumo", os estados mais bem colocados foram o Distrito Federal, o Rio de Janeiro e São Paulo. Por outro lado, o Maranhão foi aquele que apresentou os piores valores para os dois anos observados. Em 
relação à dimensão "Riqueza Real - Legado Intergeracional", o Distrito Federal se manteve como líder em 2002 e 2008, acompanhado pelo Paraná. As últimas colocações foram ocupadas pelo Mato Grosso em 2002 e pelo Piauí em 2008. Algumas alterações foram verificadas quanto às colocações dos estados de um ano para o outro da análise, sobretudo devido às modificações nos valores dos indicadores que compõem a dimensão. A dimensão "Equidade", que considera o nível de desigualdade de distribuição de renda e a intensidade de pobreza, foi liderada por Santa Catarina, Rio Grande do Sul e Paraná, refletindo as boas condições de equidade oferecidas pela região Sul do Brasil. Na contramão desse resultado, o estado de Alagoas apresentou indicadores preocupantes de equidade econômica, fazendo com que se mantivesse em último lugar no ranking da dimensão nos dois anos do estudo. Os resultados da dimensão "Seguridade Econômica" mostraram que alguns dos estados da região Nordeste apresentaram baixos riscos associados aos recursos econômicos, o que permitiu que alcançassem as primeiras colocações no ranqueamento da dimensão. Esses bons resultados se deram em decorrência dos baixos valores apresentados para os indicadores de risco, sobretudo para o risco de pobreza em idade avançada e para o risco de violência, o qual foi medido pela taxa de homicídios. Afora isto, observou-se que tanto em 2002 quanto em 2008 os estados de São Paulo, Rio de Janeiro, Distrito Federal e Amapá foram os que apresentaram o pior desempenho.

No intuito de evitar possíveis arbitrariedades quanto à escolha da melhor ponderação, o IBEE foi calculado de cinco diferentes formas - pesos iguais e maior peso para cada uma das dimensões individualmente.

O cálculo do índice, independentemente da ponderação utilizada, demonstrou que Santa Catarina é o estado brasileiro que apresenta o maior bem-estar econômico em relação aos demais. O estado, que pertence à região Sul do país, é dotado de bons indicadores para as quatro dimensões do índice, o que confere aos seus habitantes boas condições econômicas e qualidade de vida. Considerando ainda as distintas possibilidades de ponderações, observou-se que juntamente à Santa Catarina, os estados de São Paulo, Rio Grande do Sul e Paraná apresentaram elevados IBEEs em 2002 e 2008. O Distrito Federal se manteve bem colocado apenas quando o índice foi calculado com pesos iguais para todas as dimensões e ainda quando "Fluxos de Consumo" e "Riqueza Real - Legado Intergeracional" receberam maior peso, sobretudo ao analisar o ano de 2002. Verificou-se ainda que o estado com piores índices de bem-estar econômico para qualquer estrutura de ponderação e em todos os anos estudados foi Alagoas. Com exceção do ranqueamento produzido pelo IBEE calculado com maior peso para a dimensão "Seguridade Econômica” em 2002, o estado de Alagoas assumiu a última colocação em nível de bem-estar econômico em comparação aos outros estados brasileiros. 
Mostra-se clara, a partir de todo o exposto por este trabalho, a necessidade e o benefício da construção de um indicador sintético de bem-estar econômico que seja capaz de englobar os distintos aspectos que estão associados a um padrão de vida decente. A proposta é de que o índice seja composto por quatro dimensões que mensurem o consumo real das famílias e do governo, a riqueza atual e o legado deixado para as futuras gerações, a equidade na distribuição dos recursos e a intensidade de pobreza, além da seguridade associada aos aspectos econômicos. O índice é sugerido como uma medida alternativa de bem-estar econômico, sobretudo ao PIB per capita, o qual desconsidera fatores relevantes em relação ao acesso a recursos econômicos. Cabe salientar que, embora não seja possível considerar todos os aspectos relacionados ao bem-estar econômico, o IBEE busca englobar seus principais determinantes de modo simples e objetivo, utilizando-se de informações estatísticas disponíveis.

Desta forma, tendo em vista a relevância de indicadores para subsidiar a implementação e monitoramento de políticas públicas, além da necessidade de transparência sobre a situação econômica da população, o IBEE apresenta-se como um índice capaz de mensurar de maneira mais adequada o bem-estar econômico dos indivíduos.

\section{Referências}

AMORIM, A. L.; SCALCO, P. R.; BRAGA, M. J. Crescimento econômico e convergência de renda nos estados brasileiros: uma análise a partir dos grandes setores da economia. Revista Econômica do Nordeste, Fortaleza, v. 39, n. 3, p. 359-370, 2008.

ANAND, S.; SEN, A. Human development index: methodology and measurement. New York: UNDP, 1994. $25 \mathrm{p}$.

ANDRADE, M. V.; PEIXOTO, B. T. Avaliação econômica de programas de prevenção e controle da criminalidade no Brasil. Belo Horizonte: UFMG/CEDEPLAR, 2007. 30 p. (Texto para discussão, n. 311).

BRASIL. Ministério da Fazenda. Secretaria do Tesouro Nacional. Execução orçamentária dos estados (1995-2010). Disponível em: < http://www.tesouro.fazenda.gov.br/pt_PT/contasanuais >. Acesso em: 20 jun. 2011 a.

. Ministério da Previdência Social. Base de dados históricos do anuário estatístico da Previdência Social. Disponível em: < http://www.mps.gov.br>. Acesso em: 14 abr. 2010.

. Ministério de Ciência e Tecnologia. Indicadores. Disponível em: < http://www.mct. gov.br >. Acesso em: 22 jun. 2011 b.

. Ministério de Minas e Energia. Empresa de Pesquisa Energética. Consumo de energia

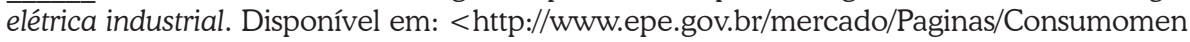
saldeenergiaelétricaporclasse(regiõesesubsistemas)-2011-2012.aspx>. Acesso em: 25 jun. 2011c. 
CANGUSSU, R. C.; SALVATO, M. A.; NAKABASHI, L. Uma análise do capital humano sobre o nível de renda dos estados brasileiros: MRW versus Mincer. Estudos Econômicos, São Paulo, v. 40, n. 1, p. 153-183, 2010.

COMMISSION FOR RURAL COMMUNITIES. Understanding economic well-being. Cheltenham: Commission for Rural Communities. 2010. Disponível em <http://www. roseregeneration.co.uk/media/understandingeconomicwellbeing1.pdf $>$. Acesso em: 10 out. 2010.

DATASUS. Departamento de informática do SUS. Disponível em: <www.datasus.gov.br>. Acesso em: 12 jun. 2011.

FIGUEIRÊDO, E. A. Ensaios sobre distribuição de renda e bem-estar econômico no Brasil. 2007. 76 f. Tese (Doutorado em Economia) - Programa de Pós-Graduação em Economia, Faculdade de Ciências Econômicas, Universidade Federal do Rio Grande do Sul, Porto Alegre, 2007.

FIGUEIRÊDO, E. A.; ZIEGELMANN, F. A. Mobilidade de renda e bem-estar econômico no Brasil. Revista Brasileira de Economia, Rio de Janeiro, v. 63, n. 4, p. 317-328, 2009.

GUIMARÃES, J. R. S.; JANNUZZI, P. M. Indicadores sintéticos no processo de formulação e avaliação de políticas públicas: limites e legitimidades. In: ENCONTRO NACIONAL DE ESTUDOS POPULACIONAIS, 14, 2004, Caxambu. Anais... Caxambu: ABEP, 2004.

IBGE Pesquisas nacionais por amostra de domicílios. Disponível em: < http://www.ibge.gov. br>. Acesso em: 20 jun. 2011 b.

. Pesquisas de orçamentos familiares. Disponível em: <http://www.ibge.gov.br $>$. Acesso em: 20 jun. 2011 a.

INSTITUTO DE PESQUISA ECONÔMICA APLICADA. Ipeadata regional. Disponível em: $<$ http://www.ipeadata.gov.br >. Acesso em: 22 jun. 2011.

JURADO, A.; PEREZ-MAIO, J. Construction and evolution of a multidimensional well-being index for the Spanish regions. Social Indicators Research, v. 107, n. 2, p. 259-279, Apr. 2011.

LANGONI, C. G. Distribuição de renda e desenvolvimento econômico e no Brasil. 3. ed. Rio de Janeiro: FGV, 2005.

ORGANIZAÇÃO PARA A COOPERAÇÃO E DESENVOLVIMENTO ECONÔMICO. Handbook on constructing composite indicators: methodology and user guide. Paris: OCDE, 2008.

OSBERG, L. The measurement of economic welfare. In: LAIDLER, D. (Coord.). Approaches to economic well-being. Toronto: University of Toronto Press, 1985. p. 49-87.

OSBERG, L.; SHARPE, A. An index of economic well-being for Canada. Hull: Applied Research Branch, 1998.

. An index of economic well-being for selected OECD countries. Review of Income and Wealth, San Francisco, v. 48, n. 3, p. 291-316, 2002. 
OSBERG, L.; SHARPE, A. New estimates of the index of economic well-being for Canada and the provinces, 1981-2008. Ottawa: Centre for the Study of Living Standards, Dec. 2009.

ROCHA, S. Alguns aspectos relativos à evolução 2003-2004 da pobreza e da indigência no Brasil. Parcerias Estratégicas, Brasília, v. 11, n. 22, p. 11-38, 2006.

SOARES, S. S. D. Metodologias para estabelecer a linha de pobreza: objetivas, subjetivas, relativas, multidimensionais. Rio de Janeiro: IPEA, 2009. (Texto para discussão, 1381).

STIGLITZ, J. E.; SEN A.; FITOUSSI, F. P. Report by the commission on the measurement of economic performance and social progress. 2009. Disponível em: < http://www.citymaking. com/wp-content/uploads/2010/01/19784660-Happiness-and-Measuring-Economic-Progressby-Joseph-Stiglitz.pdf>. Acesso em: 05 abr. 2011.

WORLD BANK. World Data Bank. Intentional homicides. Disponível em: < http://databank. worldbank.org/ddp/home.do >. Acesso em: 23 set. 2011.

Recebido em: 09/11/2013. Aceito em: 21/09/2016. 